\title{
Fertilizing the Fields for Honest Government: Reflections on leaders, leadership and Africa's challenges: Interview with Hadeel Ibrahim
}

\begin{abstract}
Ahmed Salim (AS), Programme Officer at the Regional Office of the Society for International Development, interviews Hadeel Ibrahim (HI) Director of Strategy and External Relations at the Mo Ibrahim Foundation.
\end{abstract}

AS: Five years ago the Mo Ibrahim Foundation began a bold and unorthodox attempt to promote good governance and strong leadership in Africa through the Ibrahim Prize. What do you think is the state of African leadership and democracy in 2012 compared to 2007 ?

HI: I would say that although progress is being made, I think there is not as much progress as we would have liked. The [Ibrahim] Index has demonstrated a trend of general democratic stagnation and even recession over the past five years. So the sustained economic progress and development that has been made in the past five years has not been mirrored by similar progress on the democratic front. I would say that this should be a matter of real concern, not just for citizens but governments as well. What we have seen in the Arab Spring is that even if countries are experiencing economic growth, unless that is mirrored by democratic transformation, those governments are not necessarily sustainable. There is a danger of governments purely prioritizing the economic, and assuming that greater economic growth would automatically equate to success from a governance perspective.

AS: Why do you think there has been regression with respect to leadership and governance? HI: I think the fairest term would be stagnation. If you look at the election in Senegal in the way in which the democratic credentials of that country were reaffirmed by the peaceful transition of power, and then you look at Mali and Guinea Bissau this year, whenever we do see some progress we see regression. Overall, it is probably a case of stagnation rather than progress and that is something the Foundation is really concerned about.

AS: You mentioned the Arab Spring earlier, is it too soon to say that the Arab Spring has succeeded or failed?

HI: Democracy is a work in progress and even established democracies like the United States and United Kingdom are a work in progress. I couldn't identify a perfect democracy anywhere in the world. To talk about the Arab Spring in terms of success or 
failure one year later is a dangerous thing. It is clear a huge step forward was taken through the establishment of democracies in places that were previously autocracies. But now you have very young democracies and like any young entity there are the growing pains. I think the stresses of establishing a democracy requires a complex interplay between citizens, the media, political parties, private sector and faith-based groups. We are starting to see how complex this interplay is, it is going to take a while for political parties to establish themselves, for people to decide what the role of the church/mosque is versus the state. What the role of the private sector is independent of the government. All of these things are developing so it is very hard to talk about success or failure at the moment.

AS: Should we expect to see a long Arab winter? Were people too quick to be optimistic? Were we too excited?

HI: I don't think people were too excited because having spent a lot of time in Egypt, perhaps less so in the other countries; the changing of that regime is something to be excited about and is no small achievement. For 30 years all the Egyptians I knew really bemoaned the regime, even my parent's generation would talk about the need for democratic transformation and yet it was these kids that in a matter of weeks managed to change the regime. That is incredibly exciting and an incredible achievement that we shouldn't belittle. But that was what the achievement was, an overthrow of a regime. Now there is a whole project, which is the establishment of a democratic system and an open, free and just society. In a sense it is a mistake to confuse the two things, the Mubarak regime fell but Egypt was not democratized. Democracy is a long and painful process.

AS: With reference to the debate with regards to institutions versus strong leadership. Do you think Africa needs the strongman leadership model or are we seeing a slow transition towards emboldening institutions?

HI: I think the challenge is that Africa by and large has weak institutions. Where you have weak institutions so much power is vested in the executive and the irony is you need a strong leader to 454 transfer power to the institutions. Very few people are willing to diminish their own power for the good of their country. We do by necessity have strong leaders but not the leadership that will willingly transfer power to all the institutions around them [to] really entrench governments and democracy, and in so doing weaken the position of the head of state.

AS: Leaders don't realize that a more sustainable legacy would be for them to have institutions that survive their departure from office.

HI: Exactly, because it is the only way to really entrench values and ensure sustained progress otherwise you are dependent on the kind of leader you get and as a result too much is left to chance. AS: Will there be a sub-Saharan African Spring? HI: I think that is the million-dollar question. I think that North Africa, in many ways, while demographically similar to the rest of the continent, still has significant differences. For example, a lot of sub-Saharan African countries have experienced violent conflict either within or without their borders. The propensity for people to go out on the streets and militate for good governance is diminished. The relative stability that those autocrats created in their countries probably was a factor in why people were more willing to actively protest, whereas I would think where people have had recent violent conflicts they are much more reticent to rock the boat. I think many factors come into play but in terms of a young population, when you consider amongst other factors, excessive income inequality, increasing ICT connectivity you have a lot of the fundamentals in place. So you certainly can't rule it out, but to neglect the differences would be naive.

AS: Switching gears, the narrative so far is that the youth in Africa will be the force to transform the continent. How do we square this with the crisis in education, malnutrition and unemployment?

HI: I think when we talk about the crisis in education and malnutrition we should make clear that there is progress being made in terms of human development in Africa and to neglect that would be unfair. However, once we start talking about where we need to go as a continent and where we need to be that's when the challenges are thrown into relief. In a globalized market where we are 
competing with other emerging and emerged economies, it is clear that there needs to be huge investment in education and specifically in vocational training. It is a matter of where we look at Africa: how far it has come or where it needs to be.

How we manage the entry of the 500 million Africans under the age of 19 into the labour market over the next 10-15 years in terms of both preparing them for it and matching that supply to what demand exists is going to be critical because of the sheer numbers involved. So this demographic dividend, particularly in a world where most developed countries have aging populations and it's unclear how their future work force is going to support their future retirees. Of course we have to view these young people in Africa as probably our greatest asset, but it would be foolish to think that their existence alone will lead to positive outcomes if we are not dealing with the nutrition and employment issues from now.

AS: If you look at Rwanda, agriculture is an important strategy in its development and poverty reduction strategy but you find there that the youth are not very interested in being farmers. Their demand does not match the government supply.

HI: I think that's right and maybe it's a branding issue. Of course agriculture is going to be a massive potential employer and it is one of Africa's comparative advantages when you consider the amount of uncultivated land that exists and one thing we know is people will always want food. But the disadvantage is that most young people don't envisage a modern dynamic career as being a farmer. Are we able to meet their aspirations to be active, connected dynamic citizens with a career in agriculture?

That is going to be a big challenge. But also, at the age of 16, 17 and 18 when people are making choices about where to live and work we need to present young people with better information about what their options are. Young people automatically gravitate towards cities because cities are exciting and also partly because they think that's where all the work is. But we know when we look at the unemployment rate and rates of urban poverty and the many slums across Africa attached to big cities we know that's not always the case. The point is presenting people with information so that they can make informed choices rather than following the flow of people to the bright lights of the big city and realizing that when they get there they may have made a mistake. AS: Where do you see transformation on the ground happening? What has surprised you the most, especially among the youth?

HI: In terms of transformation, it is hard to say because over the six-seven years I've been working with the Foundation it is a short time span to really see huge progress. That being said, a few years ago I was in Ethiopia and I travelled to Tigray particularly to areas that were badly hit by the notorious famine in the 1980s, the amount of work that had been done in reforestation, in constructing water sheds and when you talk to people there about their awareness of the factors that had caused the famine and what they were doing to mitigate that. While I wasn't there 20-30 years ago, it was clear that there had been a huge amount of work done. I found that to be very impressive, because it was an area indelibly associated with the horrors of a huge scale famine and to see what had been done was quite impressive.

More broadly as you travel across the continent even over the past six years and returning to cities repeatedly and Dar es Salaam is one such example. These are cities where if you do not visit for three/four years and you go back you feel very lost, as they are almost unrecognizable. There are lots of new buildings that you see, there is clearly a huge amount of economic growth happening in Africa but the caveat I would give is I'm not convinced it is trickling down to people at street level. There are lots of fancy shiny new buildings, African banks popping up, mobile phone advertising everywhere but in terms of people's standards of livings when you consider how high food prices have been over the past five years or so, I would question whether the average citizen feels better or worse off than they were five years ago? I think it is a legitimate question that we need to ask.

AS: The narrative is clear especially in East Africa, the economies have been growing, 6-7 
percent growth but to the average East African they question where their bread and butter is coming from in light of these high growth rates.

HI: Exactly so, and I think the other thing is when people see wealth being created around them their expectations increase. So the potential for real tension is quite considerable and as you said there is very clear narrative of 6-7 percent growth therefore Africa is doing great, Africans are doing great and I don't dispute that $6-7$ percent growth is a good thing but I dispute there is a necessarily linkage between 6-7 percent growth and people's lives getting better. I think that is an assumption that people have made that we need to investigate.

AS: Do you think we are too caught up on trickledown economics? Investing only in infrastructure/hard issues, and assuming that paved roads will help people in the rural areas and consequently improve the livelihoods of the poor and vulnerable?

HI: I would say that maybe there has been too much faith placed in trickle-down economics but I would also question whether we have had enough investment in infrastructure. I would applaud the African Development Bank for their work in this space but the deficits in infrastructure investment in Africa are considerable and I think there has been a global consensus over the past 10-20 years that growth is great, let the private sector in a fairly unregulated way get on with things and we will all benefit.

[But] as we are seeing that this is not the case in Europe and the US maybe it is time for Africa to look at the failure of markets elsewhere and be more strategic about its development paradigm than just replicate that unregulated private sector approach. That's not to say that I don't think that the private sector will be what develops Africa, I absolutely believe that, but we have to be very clear about what markets can deliver and what governments need to deliver and the relationship between the two and what civil society can deliver and have a much more informed conversation between all these different sectors about what their roles and responsibilities are. I think civil society is really one of the most exciting things I've seen over the past few years. The growth and increas- ing influence of civil society in Africa is something that has been transformational. It is clear that civil society can and will deliver more.

AS: Is it just a matter of striking a balance between these three stakeholders?

HI: Absolutely, and that's not to say governments have absolved their responsibilities and they can farm out the delivery of public goods and services to civil society and the private sector but I think there needs to be that kind of holistic approach to development.

AS: We have some critical elections coming up from Kenya to Tanzania, looking even further South Africa and then a possible post-Kagame Rwanda. How do you see these elections playing out? What worries you the most, what are you optimistic about?

HI: That's a tough question. I think it would be foolish knowing the challenges and how fraught some of these elections will be for us not to be putting strategies particularly around civil society to try to ensure positive outcomes. For example, I saw the work the Pan-African Solidarity did around mobilizing women against violence during the Senegalese election, creating a situation room to monitor and manage violence using civil society networks and this really lovely partnership between the women's and youth movements. I think where strategies like that have been successful we should be looking to replicate them from now so that we have the social infrastructure to support these volatile elections.

My concern would be that too often we see danger approaching and really don't do anything until it's too late. In Kenya a lot of lessons were learnt from the last time but unfortunately it's not only progressive forces that can benefit from hindsight but it could also be from people less well intentioned who also learn from what went well and what went badly so we have to ensure and support the women's, youths, faith-based group movements and ensure that the media plays a constructive role not a divisive role.

I think in the end the organization of and preparedness of civil society groups could be the determining factor in many of these countries but predicting how any of those elections will go is certainly not something I would presume to do. 
Largely because we talked about the Arab Spring earlier, I don't think there is a single person in Africa who in the winter of 2010 would have predicted that in one year all those leaders would be gone. It's impossible because of the many factors we discussed to predict, but what is possible is to be prepared and be organized.

AS: It is worrisome though because it looks like in Kenya lessons have not been learned. You look at the rhetoric and the violence occurring and what leaders are saying it's almost like nothing happened a few years ago.

HI: I think that's absolutely right but you know the civil society, people who lost family members, friends and colleagues have a responsibility to remember and to stand up and reject the rhetoric that is coming from their political leadership. In that, as in all things, this is a challenge for the Kenyan people unfortunately where sometimes there isn't great political leadership, citizens at the individual and collective have to take a leadership role. Everyone has to be accountable and hold each other accountable; neighbours have to hold each other accountable, colleagues, friends the society at large. People are going to have to make decisions about how highly they value peace and democracy.

AS: Where do you see the Foundation going in the next five years and what is the Mo Ibrahim Foundation doing in order to support Africa's transformation?

HI: I think the Foundation has sought to support Africa's transformation through these core issues of leadership and governance by really holding up, through the Prize, examples of great leadership and encouraging, particularly young Africans, to emulate them and not to believe the worst about the continent that the media rightly or wrongly projects. These young Africans may have heard of Idi Amin but have they heard of Chissano [Former President Joaquim Chissano of Mozambique]? I think in that through identifying political role models and encouraging young people to emulate them has supported the transformation of the continent.

I also think the Index is a tool for Africa's transformation. Initially, it was seen just as a tool for civil society and I am encouraged now to see governments engaging with the index and approaching us to trying to understand how they can use it to improve their own performance. This is exciting to us and of course there is the scholarship programme through which many young people across the continent have got the chance to develop their skills and we look forward to following their progress.

In terms of where the foundation is going, I think in five years with all people working in development the ultimate ideal is to put you out of business. Now do I think leadership and governance will be in such a place in five years that there will not be any need for us as an institution anymore? I think that's probably unlikely, but I would like us to be on that path and to be moving towards that point of the foundation really no longer has a role to play because of the entrenchment of good governance values and the excellence of the leadership across the continent. 